\title{
Feature-Based Molecular Networking Analysis of the Metabolites Produced by in vitro Solid-State Fermentation Reveals Pathways for the Bioconversion of Epigallocatechin Gallate
}

\author{
Hao-Fen Xie ${ }^{\dagger a}$, Ya-Shuai Kong ${ }^{\dagger a}, \mathrm{Ru}$ Ze Li ${ }^{\dagger a}$, Louis-Félix Nothias ${ }^{\mathrm{b}}$, Alexey V. Melnik ${ }^{\mathrm{b}}$, Hong Zhang ${ }^{\mathrm{a}}$, \\ Lu-Lu Liu ${ }^{\mathrm{a}}$, Ting-Ting An ${ }^{\mathrm{a}}$, Rui Liu ${ }^{\mathrm{a}}$, Zi Yang ${ }^{\mathrm{a}}$, Jia-Ping Ke ${ }^{\mathrm{a}}$, Peng Zhanga ${ }^{\mathrm{a}}$, Guan-Hu Bao ${ }^{\mathrm{a}}$, Zhong-Wen \\ Xie $^{\mathrm{a}, \mathrm{f}}$, Da-Xiang Li ${ }^{\mathrm{a}, \mathrm{f}}$, Xiao-Chun Wan ${ }^{\mathrm{a}}$, Qian-Ying Dai ${ }^{\mathrm{a}}$, Liang Zhang ${ }^{\mathrm{a}, \mathrm{f}}$, Ming Zhao ${ }^{\mathrm{d}}$, Mao-Qiang An ${ }^{\mathrm{e}}$, \\ Yan-Hua Long ${ }^{*}$, Tie-Jun Ling ${ }^{* a, f}$
}

a State Key Laboratory of Tea Plant Biology and Utilization, Anhui Agricultural University, 130 Changjiang West Road, Hefei, 230036, Anhui, P. R. China

${ }^{\mathrm{b}}$ Collaborative Mass Spectrometry Innovation Center, Skaggs School of Pharmacy and Pharmaceutical Sciences, University of California San Diego, San Diego, California 92093, United States

${ }^{\mathrm{c}}$ School of Life Sciences, Anhui Agricultural University, 130 Changjiang West Road, Hefei, 230036, Anhui, P. R. China

${ }^{\mathrm{d}}$ College of Longrun Pu-erh Tea, Yunnan Agricultural University, Kunming 650201, Yunnan, P. R. China

e Yiyang Fu Cha Industry Development Co. Ltd., 690 North Datao Road, Yiyang 413000, Hunan, P. R. China

${ }^{\mathrm{f}}$ International Joint Laboratory on Tea Chemistry and Health Effects of Ministry of Education, Anhui Agricultural University, Hefei, Anhui, P. R. China

$\dagger$ These authors contributed equally to the work.

* Corresponding authors

(telephone: +86-551-65786129; fax: +86-551-65786129; E-mail address: longyanhua@ahau.edu.cn)

(telephone: +86-551-65786401; fax: +86-551-65786765; E-mail address: lingtj@ahau.edu.cn) 


\section{ITEMs in SI-1:}

Figure S1. Photos of the 96-well plates where the 15 fungi were incubated for 4 weeks (bottom-up view).

Figure S2. PDA with (left picture) and without (right picture) direct addition of EGCG.

Figure S3. ${ }^{1} \mathrm{H}$ NMR spectra of EGCG (A) and $\beta$-CD (B) before (a) and after (b) the inclusion complexation.

Figure S4. ${ }^{1} \mathrm{H}$ NMR of compound $\mathbf{1}$.

Figure S5. ${ }^{13} \mathrm{C}$ NMR of compound $\mathbf{1}$.

Figure S6. ${ }^{1} \mathrm{H}-{ }^{1} \mathrm{H}$ COSY of compound $\mathbf{1}$.

Figure S7. HMBC of compound 1.

Figure S8. Comparison of the MS/MS spectra between fuzhuanin A (ID: 1830) and the feature with ID 2829 (in the FBMN of PT_FA.8-1 and PDA_FA.8-1).

Figure S9. Extracted ion chromatogram of $m / z, 321.0610$.

Figure S10. The result of NAP for the node with feature ID 2829 on GNPS.

Figure S11. Extended figure for FBMN of the PT or PDA incubated with the 15 fungal strains (Figure 6A related)

Figure S12. The FBMN of the features in the raw dark tea leaves (initial moisture about $30 \%)$ before and after autoclaving $\left(120^{\circ} \mathrm{C}, 20 \mathrm{~min}\right)$.

Figure S13. The anticipated oxidation products on both B- and C-rings of flavanol.

Table S1. The ${ }^{1} \mathrm{H}$ and ${ }^{13} \mathrm{C}$ NMR data of $\mathbf{1}$.

\section{References}


(A)

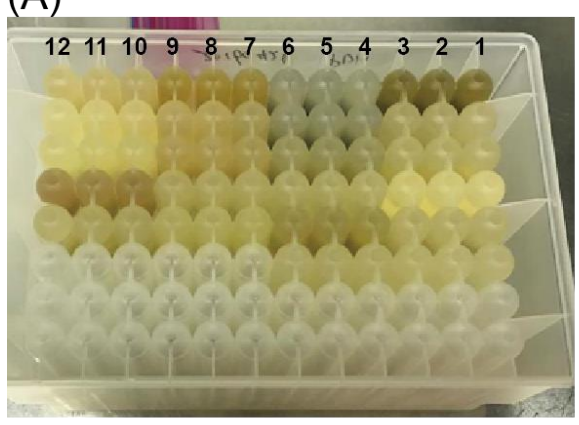

(C)

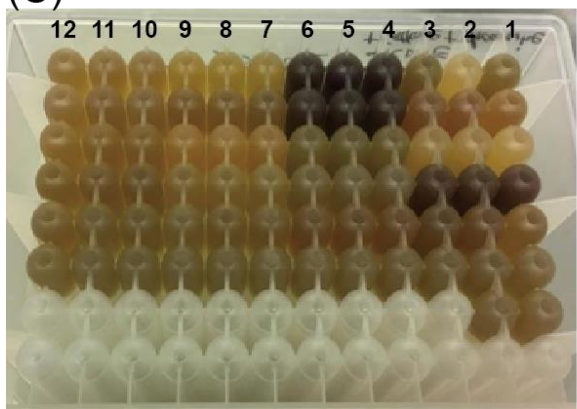

(B)

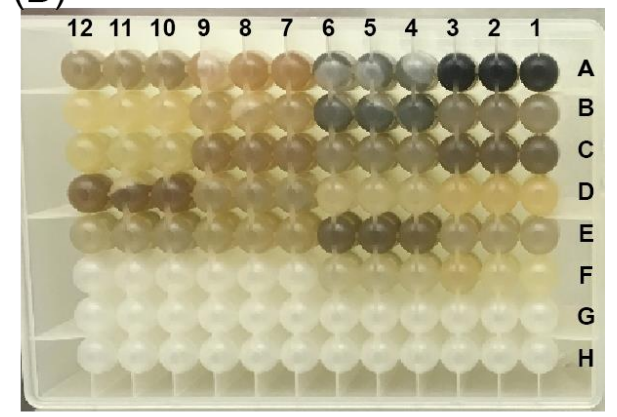

(D)

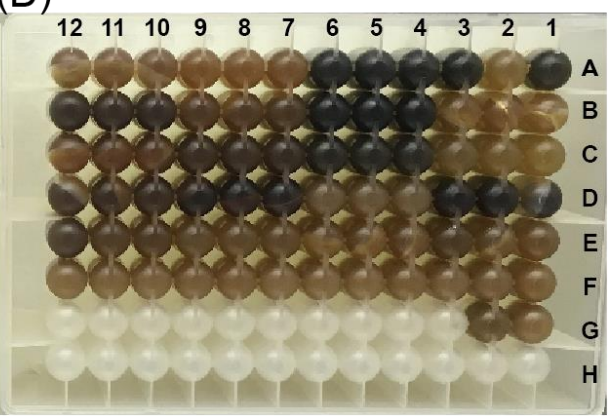

(E)

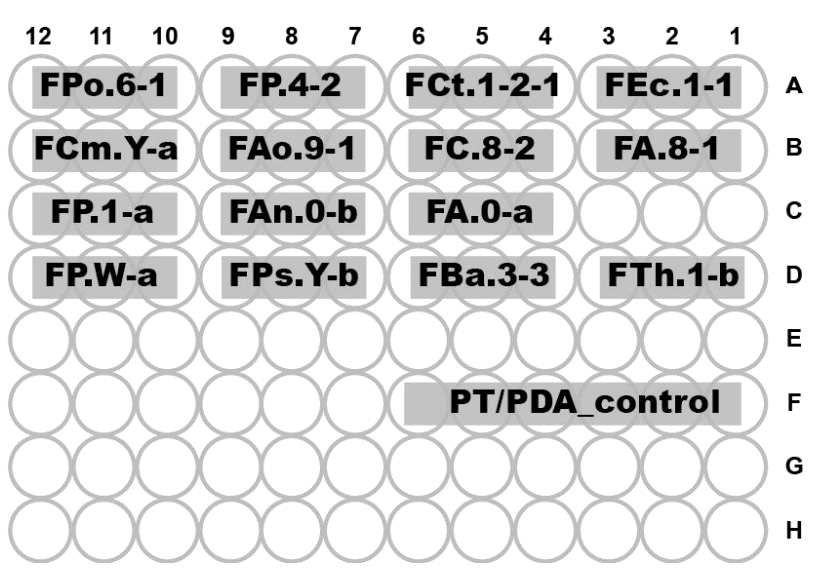

Figure S1. Photos of the 96-well plates where the 15 fungi were incubated for 4 weeks (bottom-up view). (A) One week of incubation on PDA. (B) Four weeks of incubation on PDA. (C) One week of incubation on PT. (D) Four weeks of incubation on PT. (E) The layout of the plate inoculation (bottom-up view). 


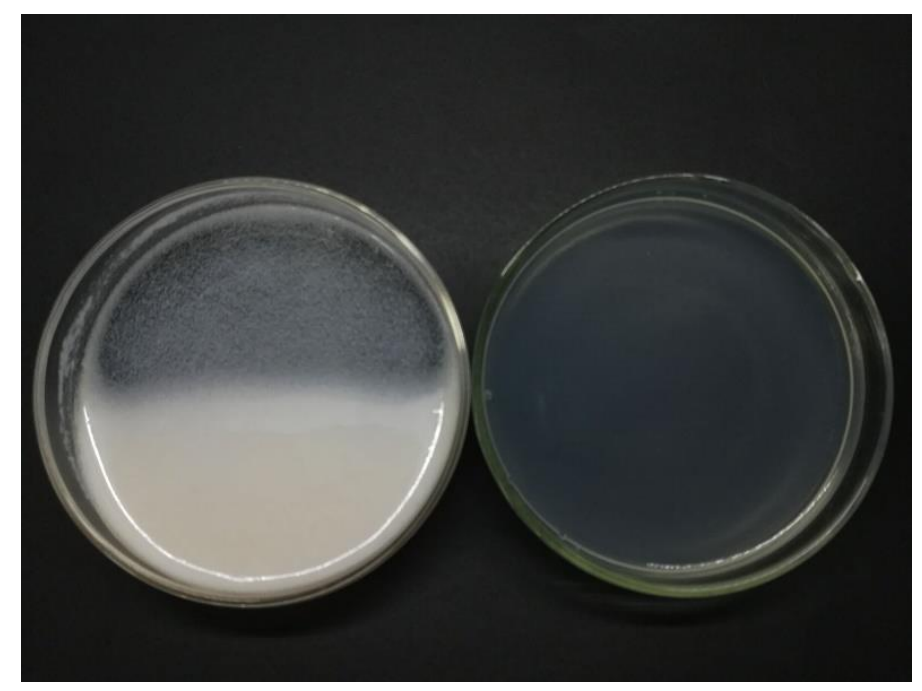

Figure S2. PDA with (left picture) and without (right picture) direct addition of EGCG.

It's interesting that when EGCG is added into PDA, the medium goes from solid to liquid. Although the mechanism is unknown, we can presume that the phenol hydroxy group in EGCG plays important role, since the inclusion complexation of the compound with $\beta$-CD neutralizes the effect (Figure S1 and S3). (The diameter of Petri dish is 9 $\mathrm{cm}$. 

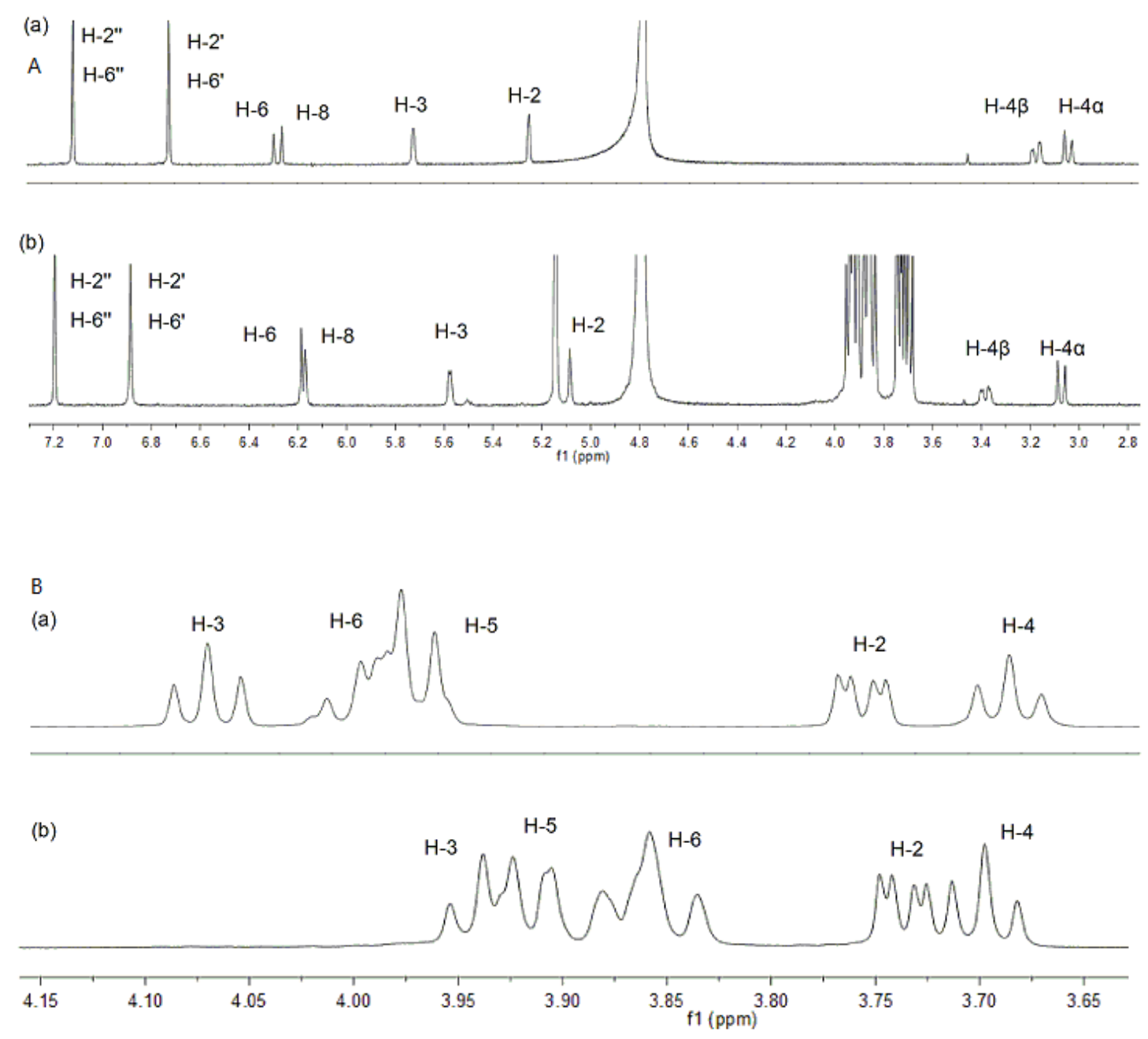

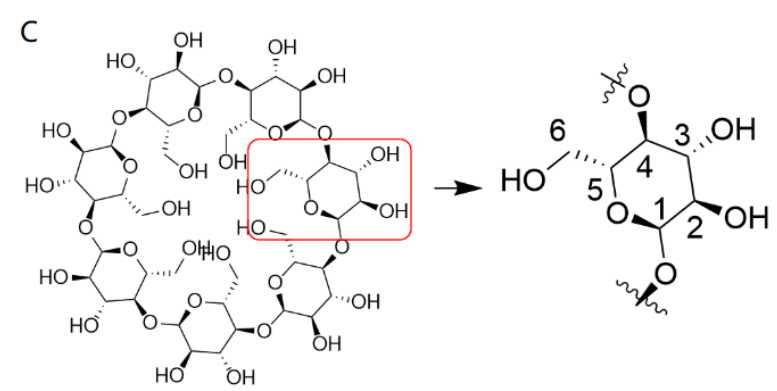

beta-CD<smiles>O=C(O[14C]1=[14CH]c2c(O)cc(O)cc2Oc2cc(O)c(O)c(O)c21)c1cc(O)c(O)c(O)c1</smiles>

EGCG

Figure S3. ${ }^{1} \mathrm{H}$ NMR spectra of EGCG (A) and $\beta$-CD (B) before (a) and after (b) the inclusion complexation.

After complexation, the peaks of H-3, H-5 and H-6 in $\beta-\mathrm{CD}$, and those of $\mathrm{H}-2, \mathrm{H}-3, \mathrm{H}-$ 6 and H-8 in EGCG, showed significant upfield shifts, while those of $\mathrm{H}-4 \beta, \mathrm{H}-2$ ', and H-6' in EGCG showed significant downfield shifts. These shifts indicated successful inclusion complexation of EGCG in $\beta$-CD. ${ }^{1}$ 


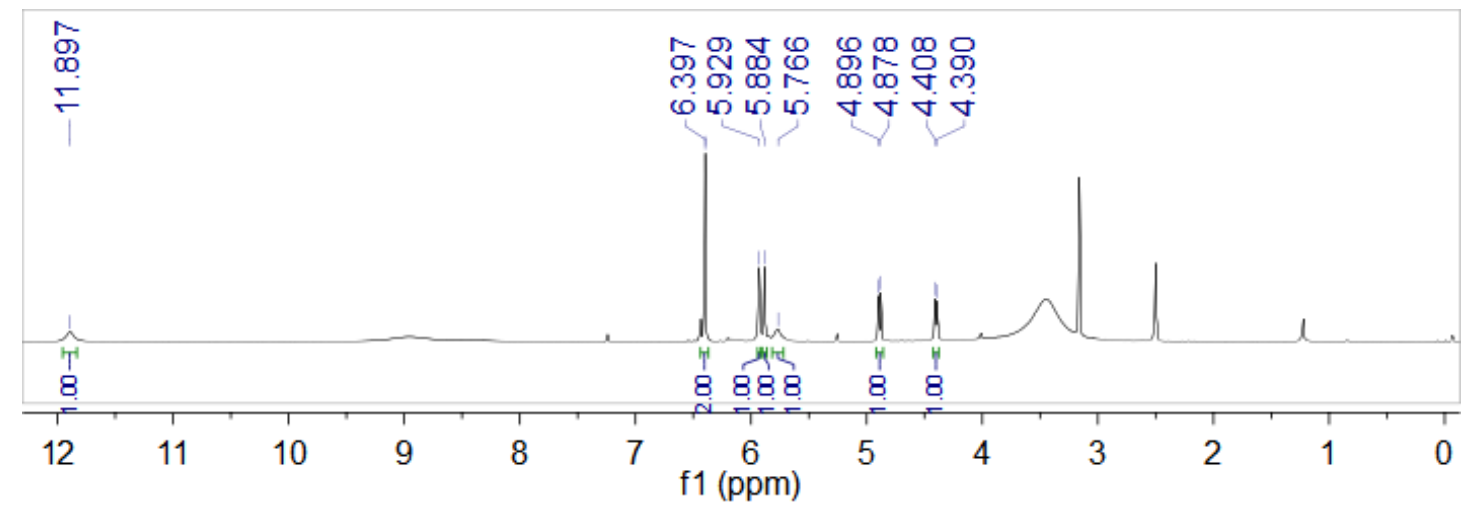

Figure S4. ${ }^{1} \mathrm{H}$ NMR of compound 1.

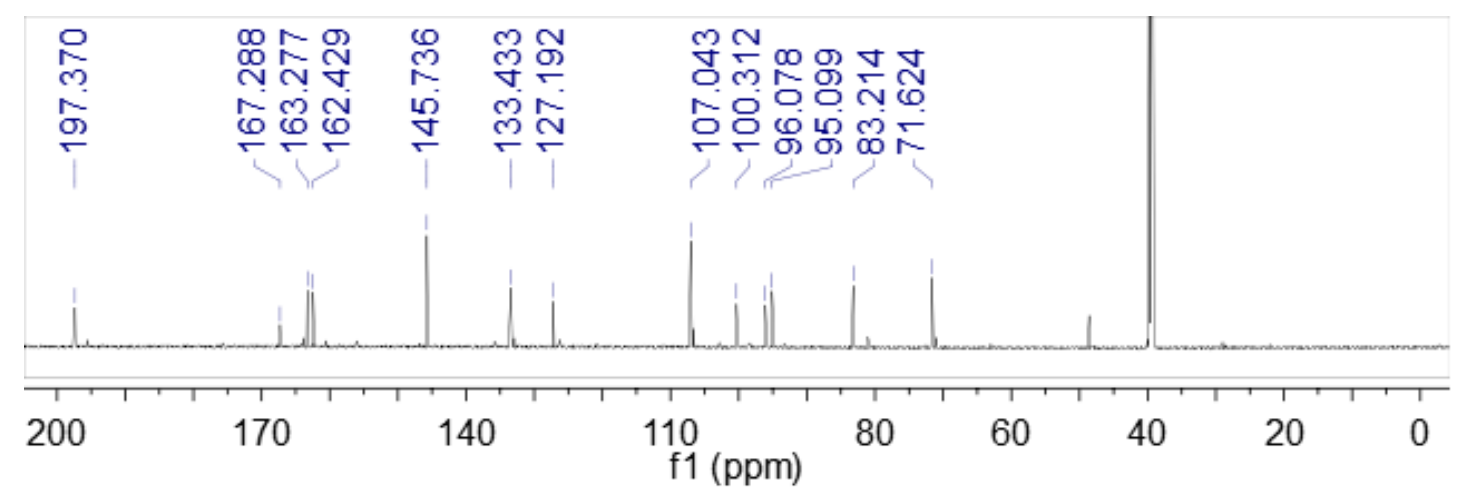

Figure S5. ${ }^{13} \mathrm{C}$ NMR of compound $\mathbf{1}$. 


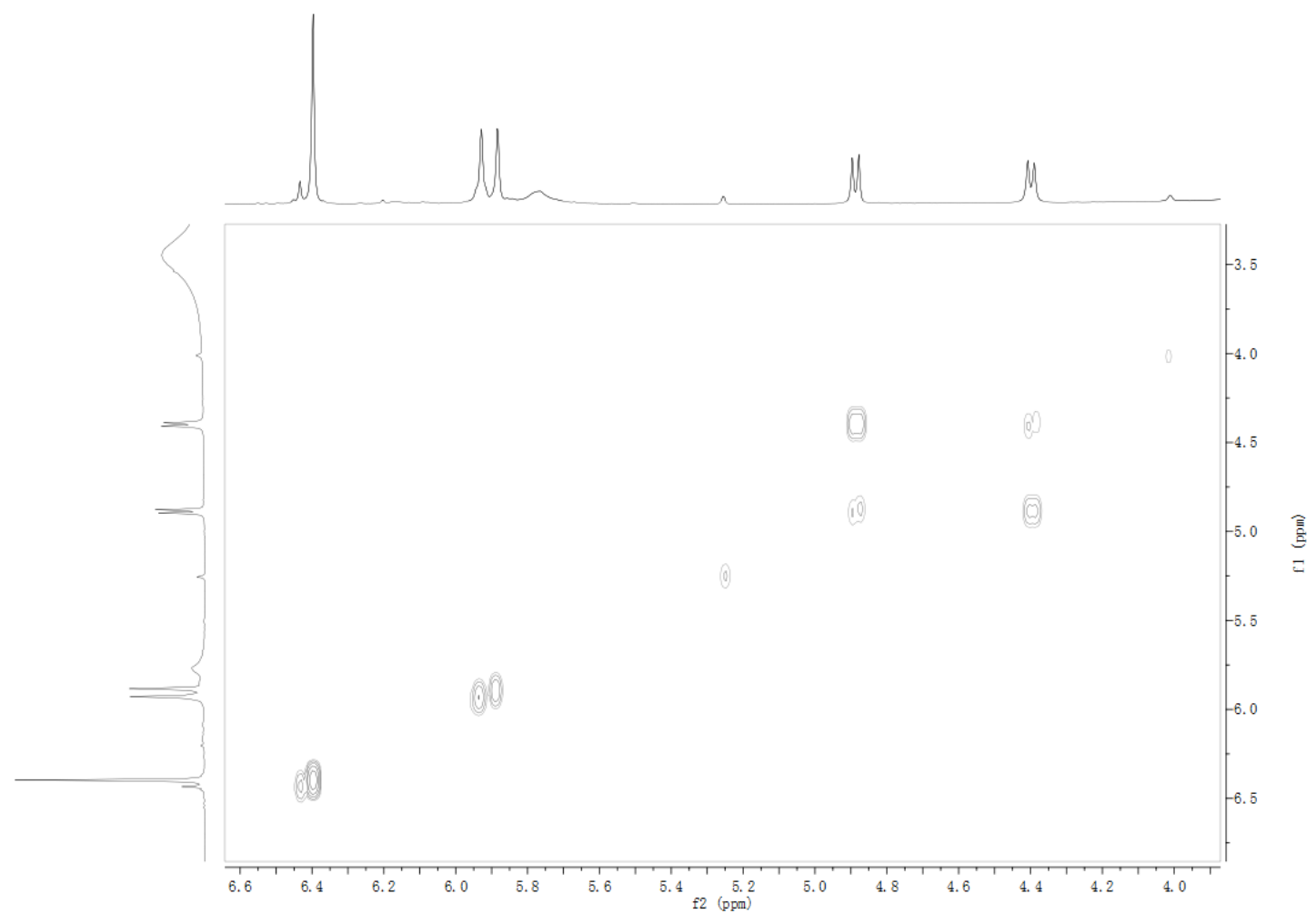

Figure S6. ${ }^{1} \mathrm{H}-{ }^{1} \mathrm{H}$ COSY of compound $\mathbf{1}$.

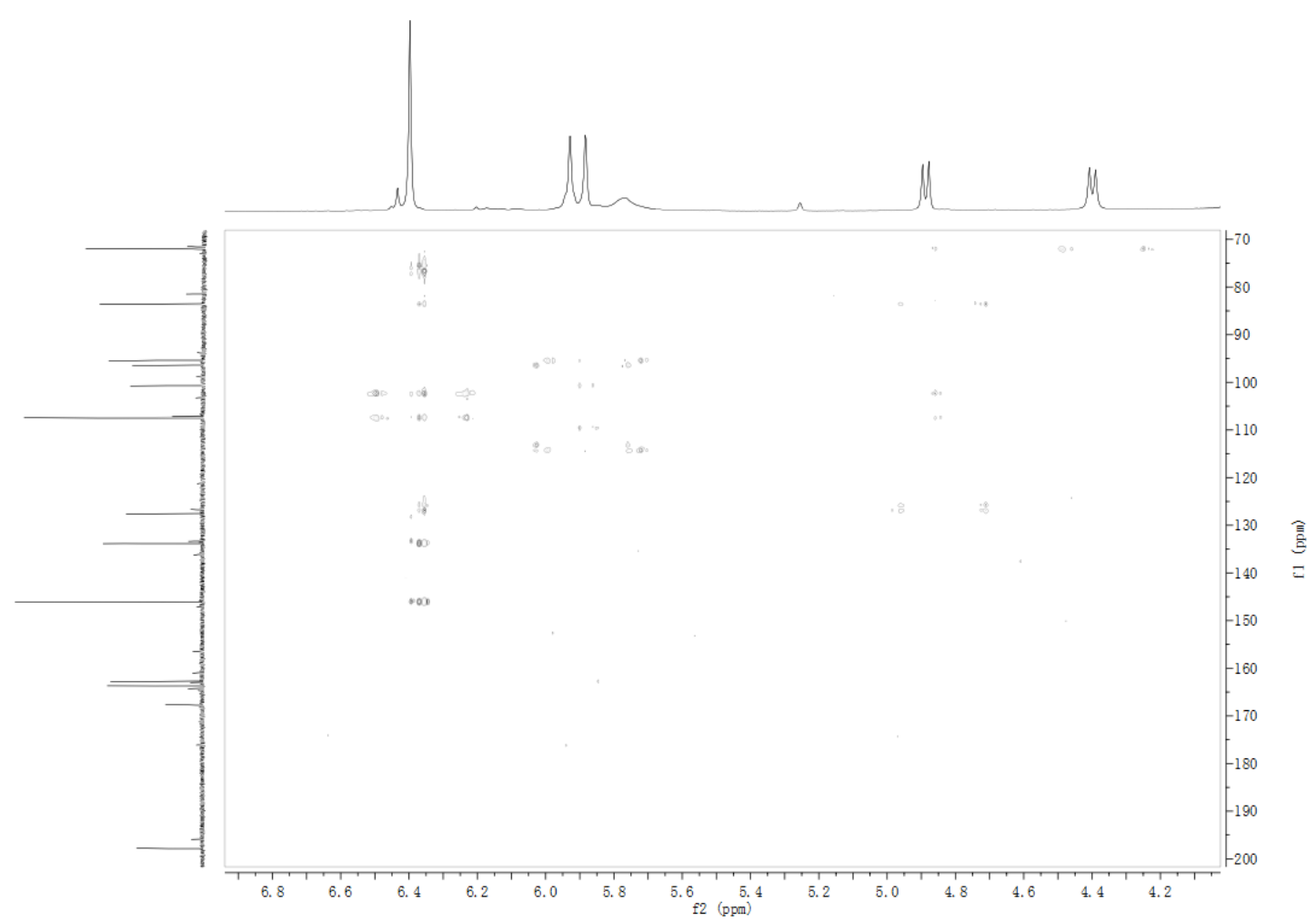

Figure S7. HMBC of compound 1. 


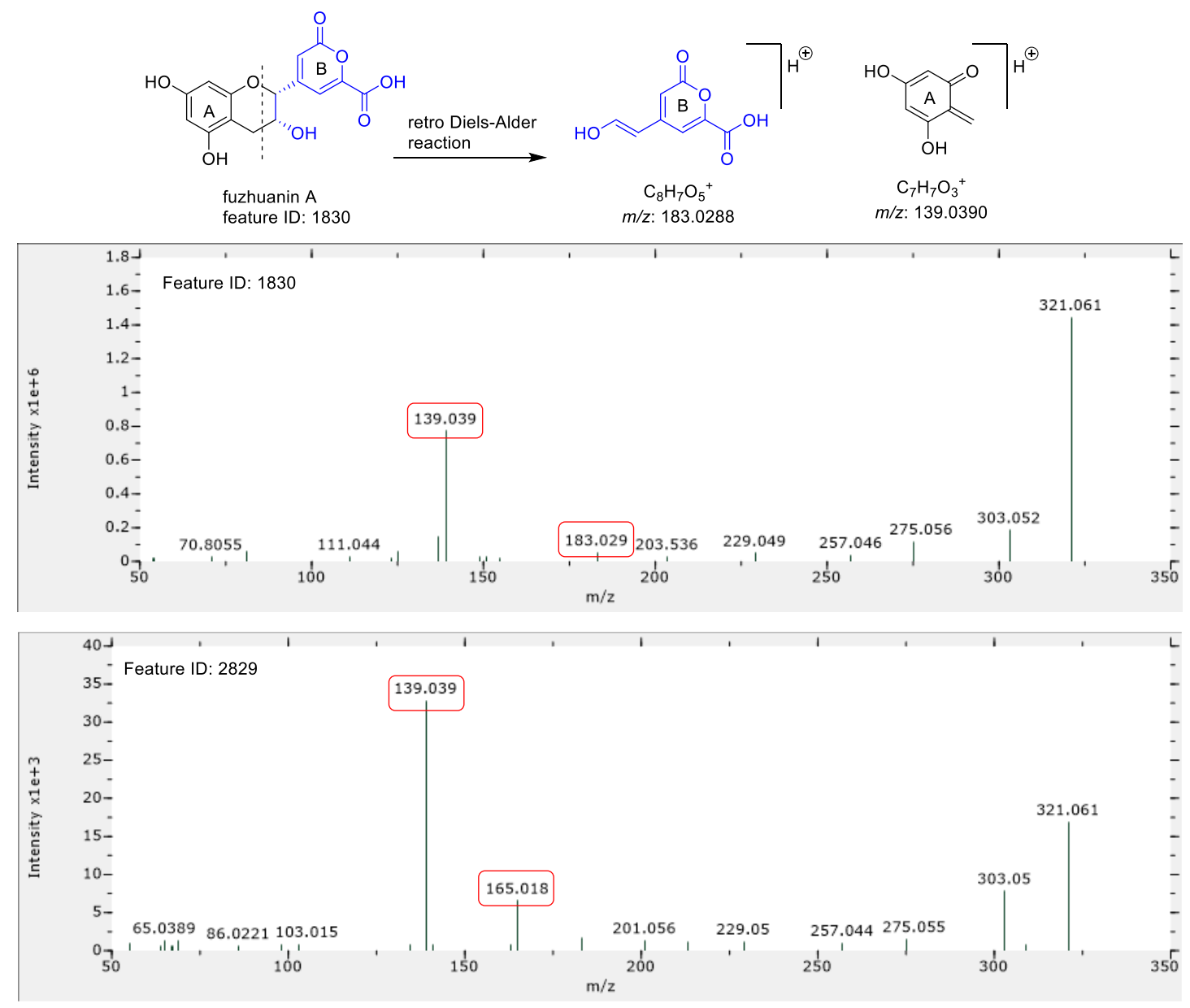

Figure S8. Comparison of the MS/MS spectra between fuzhuanin A (ID: 1830) and the feature with ID 2829 (in the FBMN of PT_FA.8-1 and PDA_FA.8-1). 


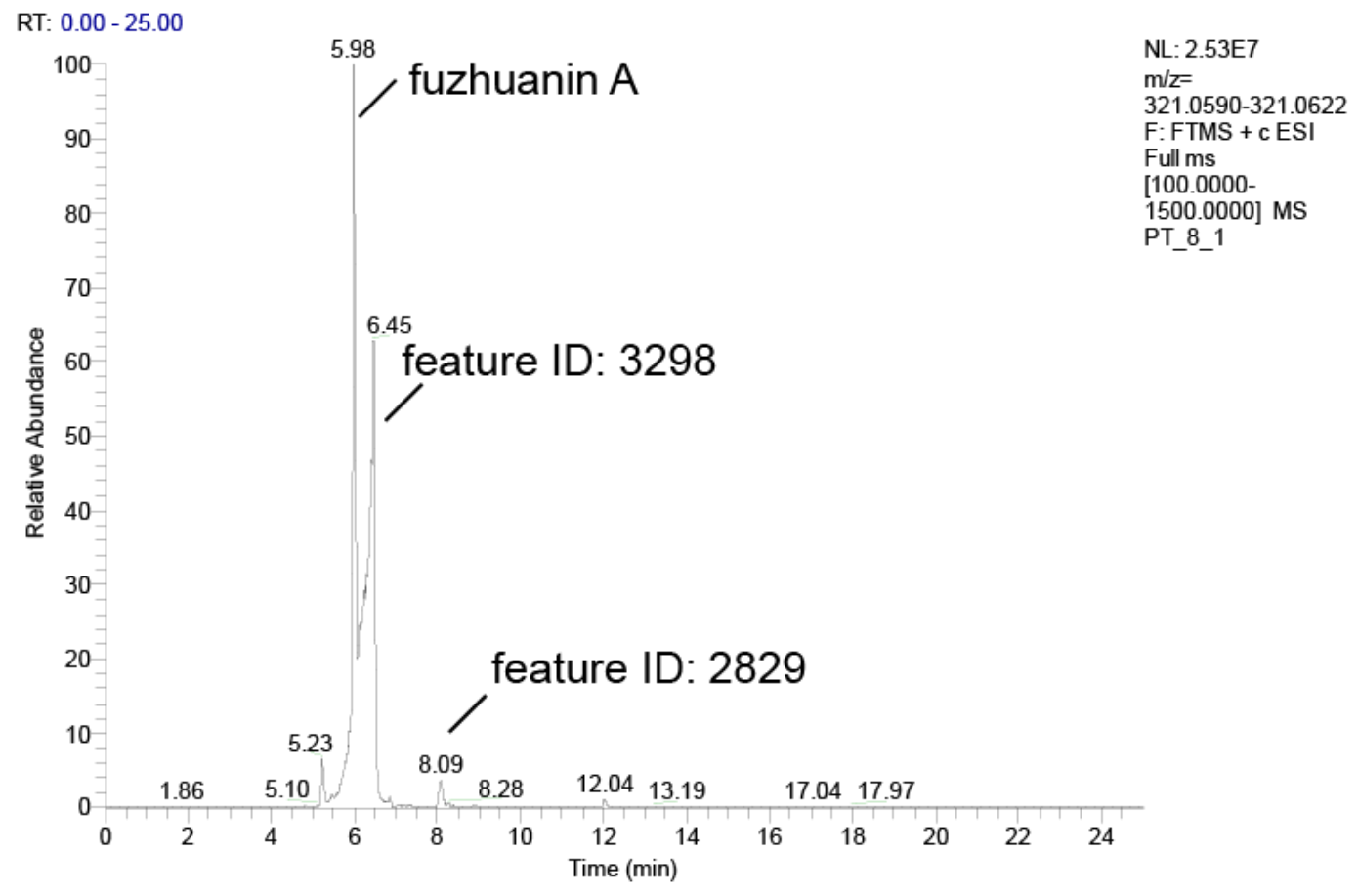

Figure S9. Extracted ion chromatogram of $m / z, 321.0610$. 


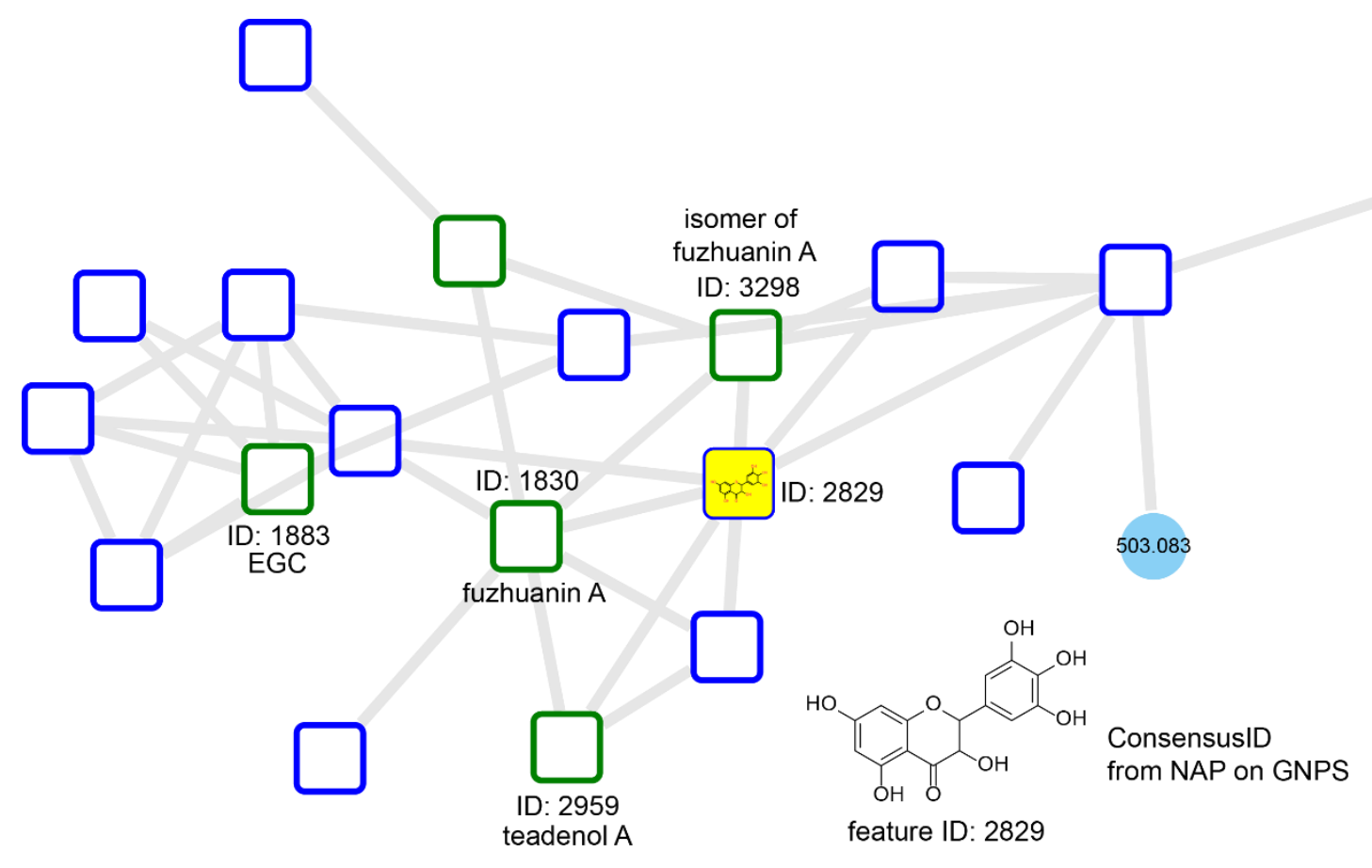

Figure S10. The result of NAP for the node with feature ID 2829 on GNPS.

The presented network is constructed by the same nodes and edges in the enlarged frame of figure 3A, which is a cluster of flavan-3-ols and their analogues. The green nodes mean those annotated by GNPS library matching. The blue ones mean those annotated by in silico prediction, including FusionID, ConsensusID and MetFragID. ${ }^{2}$ The plain structure of dihydromyricetin was successfully predicted by NAP for the feature with ID 2829. 

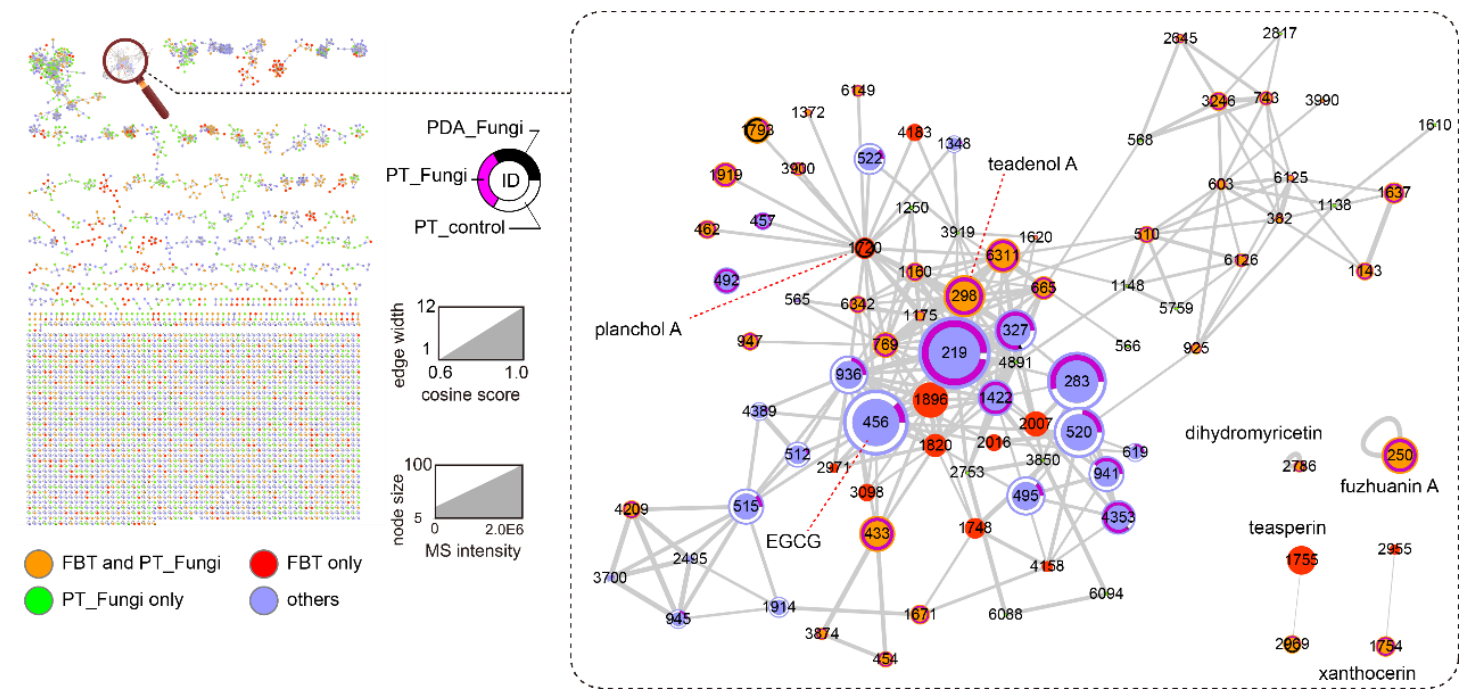

Figure S11. Extended figure for FBMN of the PT or PDA incubated with the 15 fungal strains (Figure 6A related).

As shown in the figure legends, the ring color in nodes means the average MS intensity among samples of the cultured PDA samples (black), the average MS intensity among samples of the cultured PT samples (pink), and the MS intensity in PT_control (white), respectively. The ring plot in the molecular network clearly demonstrated that the known B-ring or C-ring oxidation products were generated by fungal conversion from EGCG. Furthermore, no MS signals of these analogues were observed in the PT_control, which means the structure of EGCG was successfully protected by $\beta$-CD in the control. The FBRFAs and other flavanol analogues in the cultured PT samples were the products of bioconversion. 
A

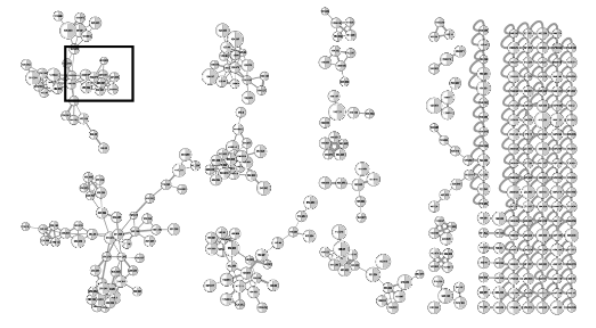

a
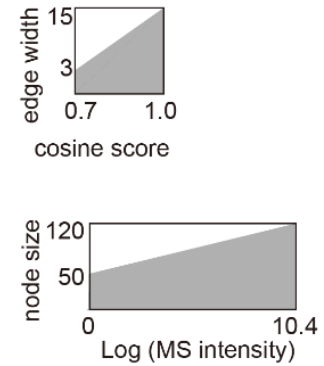

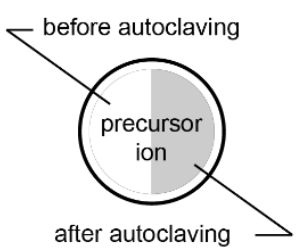

b

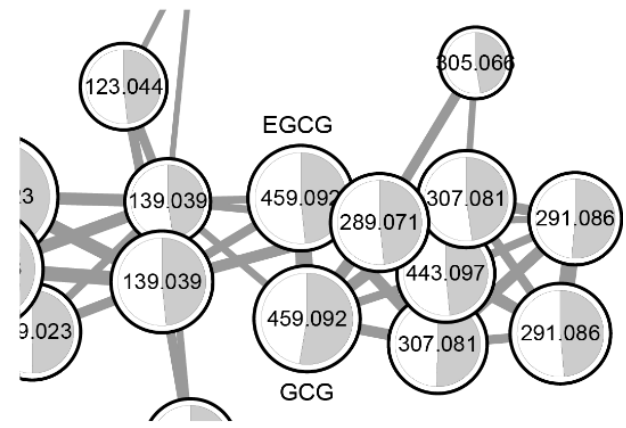

B

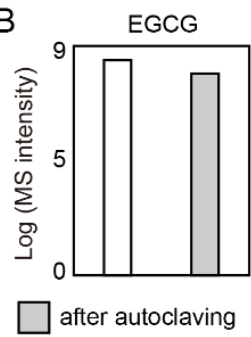

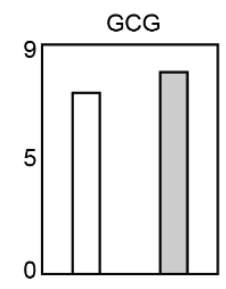

before autoclaving

Figure S12. The FBMN of the features in the raw dark tea leaves (initial moisture about $30 \%)$ before and after autoclaving $\left(120^{\circ} \mathrm{C}, 20 \mathrm{~min}\right)$.

A. FBMN of the features. a. Figure legends; b. The cluster of the features annotated as flavan-3-ol analogues, which are framed in FBMN. B. Comparison of epigallocatechin gallate (EGCG) and gallocatechin gallate (GCG) between the samples before and after autoclaving. The FBMN showed decreasing and increasing trend for EGCG and GCG, respectively. The similar phenomenon was reported in the high temperature treatment of large-leaf yellow tea. ${ }^{3}$ No feature signals for FBRFAs or dihydromyricetin were observed from the network. The result validated that the hygrothermal effect was not the reason for generation of FBRFAs or flavan-3-ol C-ring oxidation products in tea leaves. (The corresponding GNPS job status link is https://gnps.ucsd.edu/ProteoSAFe/status.jsp?task=10ca71fb9b4a48caa2feb2167fd8739d. The method of LC-MS data processing was documented in MATERIALS AND METHODS. 
<smiles>O=C(O)c1cc([C@H]2Oc3cc(O)cc(O)c3C(=O)[C@H]2O)cc(=O)o1</smiles>

C-op of fuzhuanin A

Chemical Formula: $\mathrm{C}_{15} \mathrm{H}_{10} \mathrm{O}_{9}$ $\mathrm{m} / \mathrm{z}: 335.0398$ )<smiles>COC(=O)C[C@]12OC(=O)C[C@H]1O[C@@H]1C(=O)c3c(O)cc(O)cc3O[C@H]12</smiles>

C-op of fuzhuanin D

Chemical Formula: $\mathrm{C}_{16} \mathrm{H}_{14} \mathrm{O}_{9}$ $\mathrm{m} / \mathrm{z}: 351.0711$<smiles>C=C1C=C(C(=O)O)O[C@@H]2C(=O)c3c(O)cc(O)cc3O[C@H]12</smiles>

C-op of teadenol A-B

Chemical Formula: $\mathrm{C}_{14} \mathrm{H}_{10} \mathrm{O}_{7}$ m/z: 291.0499<smiles>CC1(O)CC(=O)O[C@H]2C(=O)c3c(O)cc(O)cc3O[C@H]21</smiles>

C-op of fuzhuanin B

Chemical Formula: $\mathrm{C}_{13} \mathrm{H}_{12} \mathrm{O}_{7}$ $\mathrm{m} / \mathrm{z}: 281.0656$<smiles>CC1=CC(=O)O[C@H]2C(=O)c3c(O)cc(O)cc3O[C@H]12</smiles>
C-op of fuzhuanin E-F and xanthocerin

Chemical Formula: $\mathrm{C}_{13} \mathrm{H}_{10} \mathrm{O}_{6}$ $\mathrm{m} / \mathrm{z}: 263.0550$<smiles>CC1CC(=O)c2c1oc1cc(O)cc(O)c1c2=O</smiles>

$$
\text { C-op of teasperin }
$$

Chemical Formula: $\mathrm{C}_{13} \mathrm{H}_{10} \mathrm{O}_{5}$ $\mathrm{m} / \mathrm{z}: 247.0601$<smiles>COC(=O)C[C@@H]1[C@H]2Oc3cc(O)cc(O)c3C(=O)[C@@H]2OC1(C)OC</smiles>

C-op of fuzhuanin C

Chemical Formula: $\mathrm{C}_{16} \mathrm{H}_{18} \mathrm{O}_{8}$ $\mathrm{m} / \mathrm{z}: 339.1074$<smiles>C[C@]12OC(=O)C[C@H]1[C@@H]1Oc3cc(O)cc(O)c3C(=O)[C@@H]1O2</smiles>

C-op of teasperol and planchol A

Chemical Formula: $\mathrm{C}_{14} \mathrm{H}_{12} \mathrm{O}_{7}$ $\mathrm{m} / \mathrm{z}: 293.0656$<smiles>O=C1C=C([C@H]2Oc3cc(O)cc(O)c3C(=O)[C@H]2O)C[C@@H](C(=O)O)O1</smiles>

C-op of 6-oxo-4-(3,5,7-trihydroxy chroman-2-yl)-3,6-dihydro-2H -pyran-2-carboxylic acid

Chemical Formula: $\mathrm{C}_{15} \mathrm{H}_{12} \mathrm{O}_{9}$ $\mathrm{m} / \mathrm{z}: 337.0554$

Figure S13. The anticipated oxidation products on both B- and C-rings of flavan-3ols. ${ }^{4-9}$

C-op means C-ring oxidation product. The values after $\mathrm{m} / \mathrm{z}$ are $\mathrm{m} / \mathrm{z}$ of precursor ions $[\mathrm{M}+\mathrm{H}]^{+}$. 


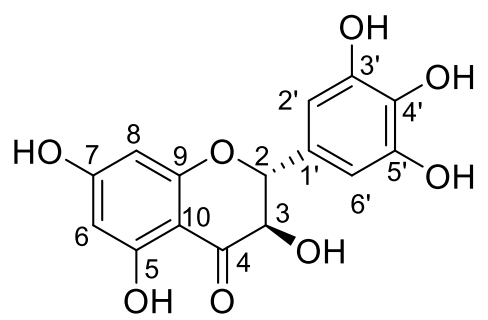

Table S1. The ${ }^{1} \mathrm{H}$ and ${ }^{13} \mathrm{C}$ NMR data of $\mathbf{1}^{a}$

\begin{tabular}{ccc}
\hline No. & $\delta_{\mathrm{C}}{ }^{b}$ & $\delta_{\mathrm{H}}(\mathrm{J} \mathrm{in} \mathrm{Hz})^{c}$ \\
\hline 2 & $83.1 \mathrm{~d}$ & $4.89 \mathrm{~d}(10.8)$ \\
3 & $71.5 \mathrm{~d}$ & $4.40 \mathrm{~d}(10.8)$ \\
4 & $197.4 \mathrm{~s}$ & - \\
5 & $162.4 \mathrm{~s}$ & - \\
6 & $96.1 \mathrm{~d}$ & $5.88 \mathrm{br} \mathrm{s}$ \\
7 & $167.3 \mathrm{~s}$ & - \\
8 & $95.1 \mathrm{~d}$ & $5.93 \mathrm{br} \mathrm{s}$ \\
9 & $162.4 \mathrm{~s}$ & - \\
10 & $100.0 \mathrm{~s}$ & - \\
$1^{\prime}$ & $127.1 \mathrm{~s}$ & - \\
$2^{\prime}$ & $106.9 \mathrm{~d}$ & $6.40 \mathrm{~s}$ \\
$3^{\prime}$ & $145.7 \mathrm{~s}$ & - \\
$4^{\prime}$ & $133.4 \mathrm{~s}$ & - \\
$5^{\prime}$ & $145.7 \mathrm{~s}$ & - \\
$6^{\prime}$ & $106.9 \mathrm{~d}$ & $6.40 \mathrm{~s}$ \\
$3-\mathrm{OH}$ & - & $5.77 \mathrm{~s}$ \\
$5-\mathrm{OH}$ & - & $11.90 \mathrm{~s}$ \\
\hline
\end{tabular}

${ }^{a}$ The data were recorded in a solvent of DMSO- $d_{6}$.

${ }^{b}$ s: quaternary carbon; $\mathrm{d}$ : $\mathrm{CH}$.

${ }^{c}$ s: singlet; d: doublet; br: broad. 


\section{References}

1. Ishizu, T.; Hirata, C.; Yamamoto, H.; Harano, K. Structure and intramolecular flexibility of $\beta$-cyclodextrin complex with (-)-epigallocatechin gallate in aqueous solvent. Magn. Reson. Chem. 2006, 44, 776-783.

2. da Silva, R. R.; Wang, M. X.; Nothias, L. F.; van der Hooft, J. J. J.; CaraballoRodríguez, A. M.; Fox, E.; Balunas, M. J.; Klassen, J. L.; Lopes, N. P.; Dorrestein, P. C. Propagating annotations of molecular networks using in silico fragmentation. PLoS Comput. Biol. 2018, 14, e1006089.

3. Zhou, J.; Wu, Y.; Long, P.; Ho, C. T.; Wang, Y.; Kan, Z.; Cao, L.; Zhang, L.; Wan, X. LC-MS-based metabolomics reveals the chemical changes of polyphenols during hightemperature roasting of large-leaf yellow tea. J. Agric. Food Chem. 2019, 67, 5405-5412.

4. Luo, Z. M.; Du, H. X.; Li, L. X.; An, M. Q.; Zhang, Z. Z.; Wan, X. C.; Bao, G. H.; Zhang, L.; Ling, T. J. Fuzhuanins A and B: the B-ring fission lactones of flavan-3-ols from Fuzhuan brick-tea. J. Agric. Food Chem. 2013, 61, 6982-6990.

5. Zhu, Y. F.; Chen, J. J.; Ji, X. M.; Hu, X.; Ling, T. J.; Zhang, Z. Z.; Bao, G. H.; Wan, $\mathrm{X}$. C. Changes of major tea polyphenols and production of four new B-ring fission metabolites of catechins from post-fermented Jing-Wei Fu brick tea. Food Chem. 2015, $170,110-117$.

6. Kanegae, A.; Sakamoto, A.; Nakayama, H.; Nakazono, Y.; Yakashiro, I.; Matsuo, Y.; Tanaka, T; Ishimaru, K. New phenolic compounds from Camellia sinensis L. fermented leaves. J. Nat. Med. 2012, 67, 652-656.

7. Wulandari, R. A.; Amano, M.; Yanagita, T.; Tanaka, T.; Kouno, I.; Kawamura, D.; Ishimaru, K. New phenolic compounds from Camellia sinensis L. leaves fermented with Aspergillus sp. J. Nat. Med. 2011, 65, 594-597.

8. Das, S.; Lamm, A. S.; Rosazza, J. P. N. Biotransformation of (+)-catechin to novel B-ring fission lactones. Org. Process Res. Dev. 2011, 15, 231-235.

9. Jiang, H. Y.; Shii, T.; Matsuo, Y.; Tanaka, T.; Jiang, Z. H.; Kouno, I. A new catechin oxidation product and polymeric polyphenols of post-fermented tea. Food Chem. 2011, $129,830-836$. 